\title{
Successful use of porcine small intestinal submucosa grafts for the treatment of a deep melting corneal ulcer in a foal
}

\author{
Alexander Schwieder, Myriam von Borstel, Julia Echelmeyer and Bernhard Ohnesorge \\ Clinic for Horses, University of Veterinary Medicine Hannover, Buenteweg 9, 30559 Hannover, Germany
}

\begin{abstract}
Summary: Severe corneal opacity and, thus, persistent visual impairment is the main risk following the treatment of keratomalacia. This report describes the successful use of commercially available porcine small intestinal submucosa (SIS) grafts (BioSIS Plus ${ }^{+}$, Vetrix ${ }^{\circledR}$ ) to treat a melting corneal ulcer in a foal. A 1 -month-old Hanoverian filly was presented with a deep melting corneal ulcer unresponsive to local medical therapy for one week. A severe ulcerative mycotic keratitis was diagnosed. Due to the high risk of corneal perforation, surgical treatment was initiated the following day. A lamellar keratectomy followed by the placement of two single overlapping multilayer porcine SIS grafts was performed under general anaesthesia. After surgery, a head bandage was placed to close the eyelids for eight days. During hospitalization, increasing transparency of the peripheral cornea was observed. The foal was discharged four weeks postoperatively. A focal pigmentation of the cornea and slight corneal oedema remained visible five months after the surgery.
\end{abstract}

Keywords: horse, cornea, keratomycosis, intestinal submucosa, graft

Citation: Schwieder A., von Borstel M., Echelmeyer J., Ohnesorge B. (2021) Successful use of porcine small intestinal submucosa grafts for the treatment of a deep melting corneal ulcer in a foal. Pferdeheilkunde 37, 243-249; DOI 10.21836/PEM20210305

Correspondence: Dr. Alexander Schwieder, Clinic for Horses, University of Veterinary Medicine Hannover, Buenteweg 9, 30559 Hannover, Germany; alexander.schwieder@tiho-hannover.de

Submitted: February 25, 2021 | Accepted: March 26, 2021

\section{Introduction}

The cornea and its thin precorneal tear film (PCTF) form a complex and fragile barrier of the visual organ against the external environment. The equine cornea is vulnerable to pathologic agents due to its large size and exposure. Direct trauma and different infectious and non-infectious diseases can destruct the ocular surface, which typically results in temporary or prolonged loss of transparency, impairing visual function (Brooks et al. 2017). Ulcerative keratitis is a common and potentially blinding ocular disease in horses, with the risk of corneal perforation within 24 hours (Strubbe et al. 2000).

Corneal wound healing is a complex interdependent process of different cellular and acellular components aiming to restore the smoothness, integrity and function of the ocular surface. It depends on the mitosis and centripetal migration of healthy epithelial cells to cover the ulcer site and their subsequent attachment to the injured corneal stroma (Wilson et al. 2001). Different proteolytic enzymes and their inhibitors participate in controlling the tissue turnover during health and disease (Sivak and Fini 2002, Ollivier et al. 2007, Brooks et al. 2017). These enzymes derive from the PCTF, corneal epithelial cells, keratocytes, infiltrating inflammatory cells and infectious organisms. In the event of corneal damage, they can provoke and enhance proteolytic activity (Kessler et al. 1977, Zhu et al. 1990, Matsubara et al. 1991, Twining et al. 1994a, Twining et al. 1994b, Matsumoto 2000 , Strubbe et al. 2000). The imbalance in the healing progression and enhanced proteolytic activity results in the liquefaction and gelatinization of the corneal stroma, which is described by the term "melting ulcer" or "keratomalacia" (Fini et al. 1998). This pathologic process was observed in different species but is thought to be most harmful in horses (Brooks 1999, Ollivier 2005, Ollivier et al. 2007). Previous studies showed that the matrix metalloproteinases (MMPs) MMP-2 and MMP-9 and a serine proteinase (neutrophile elastase) play a key role during this pathologic condition (Fini et al. 1998, Strubbe et al. 2000, Sivak and Fini 2002, Ollivier et al. 2007). A study focusing on proteinases of the equine PCTF showed that median MMP-2, MMP-9 and neutrophil elastase levels were significantly higher in ulcerated eyes compared to normal controls. The MMP-2 levels were even significantly elevated in the PCTF of the contralateral eyes of affected horses (Strubbe et al. 2000). Proteolytic activity decreases at the time of ulcer healing. In the case of "melting" ulcers, proteinase levels remain elevated, leading to rapid progression of the ulcer.

The medical treatment of corneal ulcers aims primarily to eliminate provoking agents and decrease collagenolysis and reflex uveitis (Brooks et al. 2017). Deep corneal ulcers which affect more than $50 \%$ of the total corneal thickness or inefficiency of medical treatment require consistent surgical intervention (Nasisse and Nelms 1992, Brooks 2008, Brooks et al. 2017). The aim of surgical treatment is to provide an immediate supply of fibroblasts, growth factors and protease inhibitors in combination with giving 
structural support by using different biomaterial grafts ( $\mathrm{Na}$ sisse and Nelms 1992, Brooks 2008, Brooks et al. 2017). Appropriate graft material has to fulfil different biological and economical requirements for its use in veterinary medicine. The successful use of different biomaterials including equine amnion (Lassaline et al. 2005, Plummer 2009), porcine urinary bladder (Mancuso et al. 2016, Cichocki et al. 2017, Davis et al. 2019) and porcine small intestinal submucosa (SIS) (Bussieres et al. 2004) in the surgical treatment of corneal defects in equine patients has been reported. Transplantation of full or split thickness allogenic corneal grafts is also a valid option to treat corneal defects in horses (Whittaker et al. 1997, Andrew et al. 2000, Lassaline et al. 2005, Brooks et al. 2008, Brooks 2010, de Linde Henriksen et al. 2012) but requires the availability of fresh or frozen cornea from donor horses.

SIS is a non-immunogenic, acellular collagen matrix derived from porcine jejunum (Lewin 1999, Bussieres et al. 2004, Featherstone and Sansom 2004, Vanore et al. 2007). SIS grafts are composed of the tunica muscularis mucosa, tunica submucosa and the stratum compactum layer of the tunica mucosa. The mesenteric tissue, tunica mucosa, serosa and tunica muscularis are mechanically removed before the remaining tissue is decellularized (Bussieres et al. 2004). Former studies describe the experimental and clinical use of SIS grafts as a scaffold medium for regeneration in different types of tissue, such as vessels, fascia, dura, tendons and ligaments (Badylak et al. 1989, Lantz et al. 1990, Aiken et al. 1994, Cobb et al. 1999, Suckow et al. 1999, Dejardin et al. 1999, Gastel et al. 2001, Derwin et al. 2004, Fiala et al. 2007, Ding et al. 2015). These SIS grafts have repeatedly been used for the reconstruction of infected or non-infected corneal defects in canine (Lewin 1999, Bussieres et al. 2004, Vanore et al. 2007, Goulle 2012) and equine patients (Bussieres et al. 2004) with limited complications. In previous reports, SIS grafts were additionally covered with a conjunctival (Lewin 1999, Bussieres et al. 2004) or third eyelid flap (Vanore et al. 2007, Goulle 2012) to support tissue integrity.

\section{Case History}

A 1 -month-old Hanoverian filly was referred to the Clinic for Horses at the University of Veterinary Medicine Hanover with a history of deep corneal ulceration of the left eye. Before admission, the foal had been unresponsive to local treatment with gentamycin, neomycin, polymyxin B and dexamethasone for one week.

\section{Clinical findings}

For the examination procedure the foal was sedated with detomidine ('Cepesedan ${ }^{\circledR} 10 \mu \mathrm{g} / \mathrm{kg}$ bwt i.v.), and butorphanol ('Butorgesic ${ }^{\circledR}, 25 \mu \mathrm{g} / \mathrm{kg}$ bwt i.v.). Clinical examination of the left eye revealed severe blepharospasm, epiphora, purulent ocular discharge, photophobia and severe corneal opacification (Fig. 1a). Detailed inspection of the cornea, including slit lamp investigation, showed a central marked rounded area $(25 \times 15 \mathrm{~mm})$ of deep stromal ulceration. Fluorescein application on the corneal surface resulted in generalized staining of the defect with decreased intensity at the central area. The entire corneal surface surrounding the defect showed marked oedema with distinct opacification. The limbal area showed a narrow rim of multiple tiny blood vessels. The menace response was questionable and the pupillary light reflex could not be investigated due to the opacification of the whole cornea. Further investigation by direct or indirect visualisation of the globe was ineffective. Severe miosis was the only abnormality observed in the ultrasonographic examination. Cytologic examination showed the existence of fungal hyphae on the corneal surface, microbiological culturing revealed a mild content of Staphylococcus haemolyticus, Weissella confusa and Bacillus species. A mycotic ulcerative keratitis with subsequent keratomalacia was diagnosed.

\section{Treatment}

The foal was hospitalised and topical medical treatment was initiated with sodium-EDTA ( ${ }^{2}$ Regoculan $\left.{ }^{\circledR}\right)$, n-Acetylcysteine $\left({ }^{3}\right.$ N.A.C. Collyre Cicatrisant $\left.{ }^{\circledR}\right)$, moxifloxacin $\left({ }^{4} V_{\text {igamox }}{ }^{\circledR}\right)$, voriconazole $\left({ }^{5} \mathrm{VFEND}^{\circledR}\right)$ and atropinsulfate ( ${ }^{6}$ Atropin-POS $\left.{ }^{\circledR}\right)$. Initial treatment included systemic anti-inflammatory treatment with flunixin-meglumin ('Flunidol $5 \%{ }^{\circledR}, 1.1 \mathrm{mg} / \mathrm{kg}$ bwt per os, b.i.d.). Within the first day of treatment the foal was unresponsive to medical therapy and clinical findings worsened significantly. Due to the high risk of corneal perforation associated with ongoing corneal melting, surgical treatment was conducted the following day (Fig. 1b).

Prior to surgery, the foal received trimethoprim-sulfadiazine ( ${ }^{7}$ Synutrim ${ }^{\circledR}, 30 \mathrm{mg} / \mathrm{kg}$ bwt per os) and tetanus serum (2Tetanus-Serum ${ }^{\circledR}, 5 \mathrm{ml}$ i.m.). The foal was sedated with $x y$ lazine ('Xylavet ${ }^{\circledR}, 0.4 \mathrm{mg} / \mathrm{kg}$ bwt i.v.) and butorphanol ('Butorgesic $^{\circledR}, 25 \mu \mathrm{g} / \mathrm{kg}$ bwt i.v.) pre anaesthesia. General anaesthesia was induced with ketamin ( ${ }^{7}$ Narketan ${ }^{\circledR}, 2.5 \mathrm{mg} / \mathrm{kg}$ bwt i.v.) and diazepam $\left({ }^{8} Z_{\text {Ziapam }}{ }^{\circledR}, 0.1 \mathrm{mg} / \mathrm{kg}\right.$ bwt i.v.) and maintained with isoflurane ('Isofluran $\mathrm{CP}^{\circledR}$ ) delivered in $100 \%$ oxygen, xylazine ('Xylavet ${ }^{\circledR}, 0.6 \mathrm{mg} / \mathrm{kg}$ bwt/h CRI i.v.) and dobutamine CRI ( ${ }^{9}$ Dobutamin-ratiopharm ${ }^{\circledR}, 0.6-1.2 \mu \mathrm{g} / \mathrm{kg}$ bwt $/ \mathrm{min}$ i.v. to effect). Atracurium ( ${ }^{10}$ Atracurium-hameln ${ }^{\circledR}, 0.1 \mathrm{mg} / \mathrm{kg}$ bwt i.v.), a systemic paralytic muscle relaxant, was administered intraoperatively to facilitate proper globe position. Hence, artificial ventilation was conducted.

A keratectomy of the infected and necrotic parts of the cornea was performed using a \#64 Beaver microsurgical blade. The remaining cornea was flushed with $5 \% \mathrm{~N}$-acetylcysteine ( ${ }^{3}$ N.A.C. Collyre Cicatrisant ${ }^{\circledR}$ ) and coated with carboxymethylglucose-sulfate ( $\left.{ }^{11} \mathrm{Clerapliq}^{\circledR}\right)$. Two commercial multilayer SIS grafts ( ${ }^{12}$ Vetrix ${ }^{\circledR}$ BioSIS Plus ${ }^{+} 15$ mm Multi-layer Ocular Discs) were fitted adjacent to the corneal defect and placed side by side with a small overlap at the central border. The grafts were sutured to the cornea at their border using multiple simple interrupted sutures $\left({ }^{13} \mathrm{Vicryl}{ }^{\circledR}, 8-0\right.$ USP) (Fig. 1c). After the placement of the two patches, $0.2 \mathrm{ml}$ of $1 \%$ voriconazol $\left({ }^{5} V_{F E N D}{ }^{\circledR}\right)$ was injected into the anterior chamber of the eye. A subpalpebral lavage catheter was placed to enable topical medication of the cornea postoperatively. The eyelids were closed, covered with moistened swabs and a head bandage was applied using an elastic adhesive bandage ( $\left({ }^{14}\right.$ Equi-Plast $\left.{ }^{\circledR}\right)$ to protect the grafts following surgery. 
The foal was treated postoperatively with oral trimethoprim-sulfadiazine ( ${ }^{7}$ Synutrim ${ }^{\circledR}, 30 \mathrm{mg} / \mathrm{kg}$ bwt per os b.i.d.) and flunixin-meglumin ('Flunidol $5 \%, 1.1 \mathrm{mg} / \mathrm{kg}$ bwt, per os, b.i.d.) for five days. Topical medication of the left eye was continued after surgery with moxifloxacin $\left({ }^{4} V_{i g a m o x}{ }^{\circledR}\right)$, sodium-EDTA ( ${ }^{2}$ Regoculan $\left.{ }^{\circledR}\right)$, voriconazol $\left({ }^{5}\right.$ VFEND $\left.{ }^{\circledR}\right)$ and autologous serum every three hours and atropinsulfate $\left({ }^{6}\right.$ Atropin-POS ${ }^{\circledR}$ ) twice daily by using the subpalpebral lavage catheter. The foal showed mild diarrhoea at day five after surgery, hence, systemic medication was stopped.
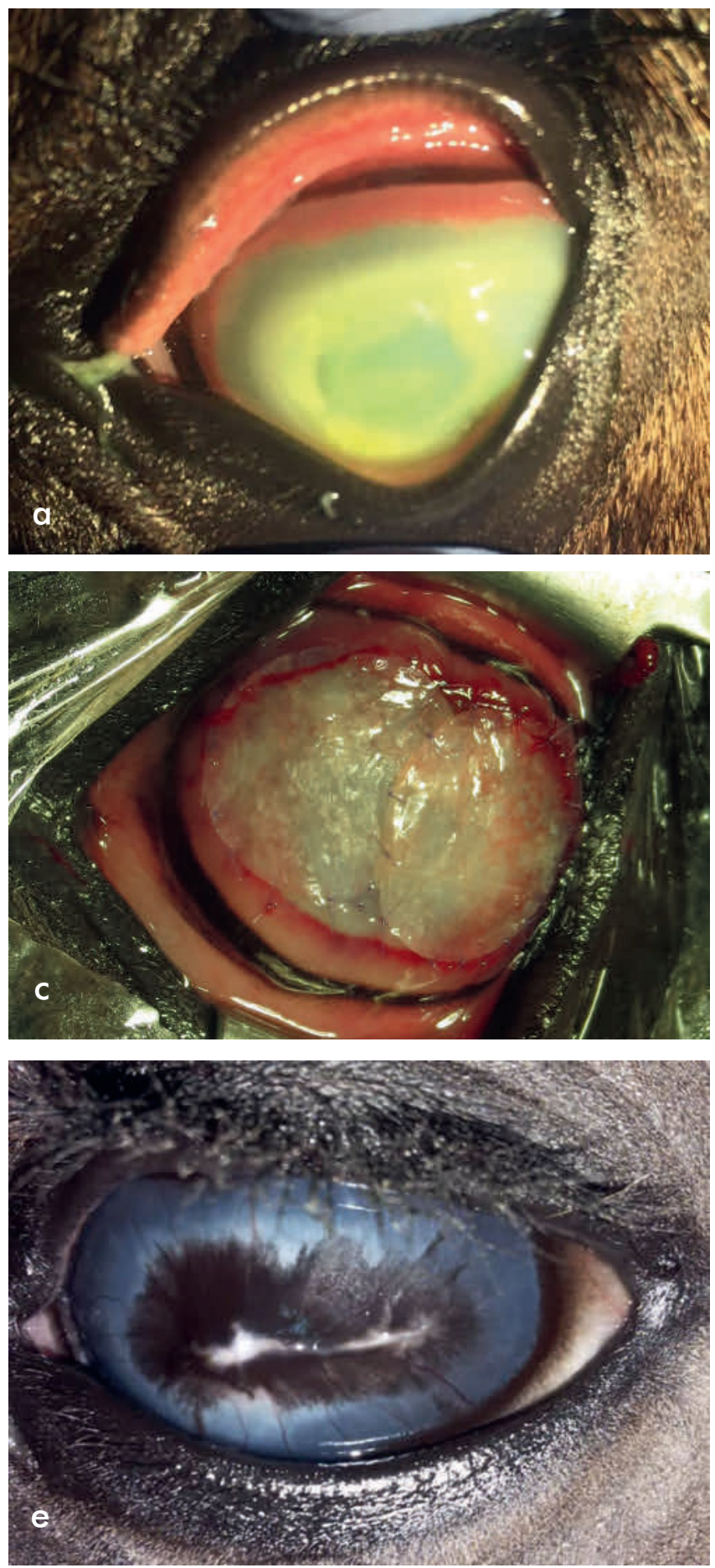

Faecal output showed no further abnormalities in the following days.

The head bandage was changed at day three and six after surgery. At day six post-surgery, subjective evaluation revealed a mild loss of intraocular pressure, additionally one of the grafts showed decreased thickness at the non-overlapping part. All sutures were still in place. At day eight, intraocular pressure seemed unremarkable, but the lower lid showed mild entropion. Coverage by a head bandage was discontinued
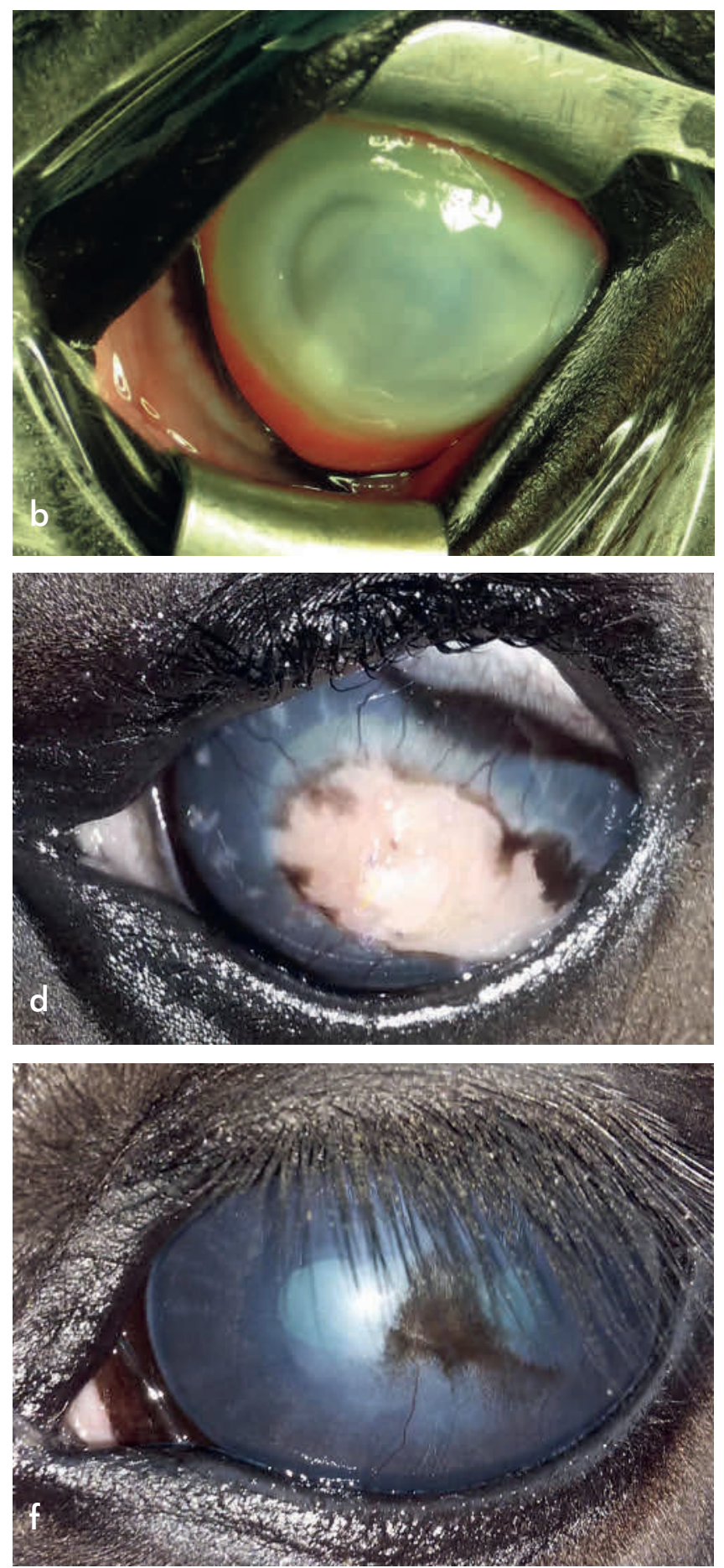

Fig. 1 Photograph of the left eye: a) at the time of presentation; b) and c) at the day of surgery, b) before and c) after surgery; d) four weeks post-surgery; e) six weeks post-surgery; f) five months post-surgery | Foto des linken Auges: a) zum Zeitpunkt der Vorstellung; b) und c) am Tag der Operation, b) vor und c) nach der Operation; d) vier Wochen nach der Operation; e) sechs Wochen nach der Operation; f) fünf Monate nach der Operation. 
at this time and the entropion was corrected manually several times a day. The subpalpebral lavage system was left in situ for the time of hospitalization. Increasing cell proliferation and peripheral corneal neovascularization was observed from day ten postoperatively. Furthermore, the entropion was no longer present.

At the time of discharge, the SIS graft material was completely integrated into the opaque granulation tissue and multiple marked vessels surrounded the former defect (Fig. 1d). The foal was discharged four weeks postoperatively.

\section{Outcome}

Follow-up information is available until five months postoperatively. After discharge, the foal underwent clinical examination at six weeks and five months postoperatively by one of the authors. At six weeks postoperatively, the corneal surface affected was still opaque and substantially darkened (Fig. 1e). However, at five months postoperatively, the transparency of the affected cornea had significantly increased and neovascularization of the cornea had decreased comparably. A small pigmented scar at the central area of the cornea, mild vascular ingrowth and a minor oedema was still visible (Fig. 1f). No ocular discomfort was present at any after discharge. Dazzle reflex was positive at each time of examination.

\section{Discussion}

Different infectious and non-infectious agents can cause infiltrative ulcerative keratitis with keratomalacia. Infectious disease primarily includes bacterial and fungal keratitis. Viral keratitis is a rare condition. Non-infectious disease includes foreign body penetration, sterile keratitis and eosinophilic keratoconjunctivitis. Nonulcerative conditions, such as immune-mediated keratitis, stromal abscess formation, calcific band keratopathy or corneal neoplasia also need to be considered (Brooks et al. 2017).

In the present case, a mycotic ulcerative keratitis with keratomalacia was diagnosed. Fungal keratitis is one of the most common ophthalmologic disease in horses. Due to the horse's environment different fungi, especially Aspergillus and Fusarium subspecies, are present on the equine conjunctiva and cornea (Whitley et al. 1983, Samuelson et al. 1984, Moore et al. 1988, Sherman et al. 2017). Corneal traumata can enable these fungi to easily enter the deep corneal stroma. Furthermore, defects in the equine corneal immune system in combination with the large exposed corneal surface make horses more susceptible for keratomycosis than other species (Andrew et al. 1998, Galán et al. 2009, Brooks et al. 2013). Before admission, the foal was treated with local antimicrobial and corticosteroid medication. Although the findings of the ophthalmologic examinations before admission are unknown, worsening of the corneal damage due to corticosteroid therapy has to be assumed. Topical corticosteroid therapy is known to interfere with cellular immunity, corneal re-epithelization, vascularization and delay of non-specific inflammatory response (Andrew et al. 1998, Thomas 2003, Galán et al. 2009). Moreover, an association between corticosteroid therapy and the formation of keratomycosis is assumed because corticosteroids can inhibit growth of nonpathogenic bacterial strains and thus enhance fungal replication (Coad et al. 1985, Brooks et al. 1998, Sansom et al. 2005, Ledbetter et al. 2007). However, two studies showed no difference in the outcome of horses suffering from keratomycosis after pretreatment with local corticosteroids (Galán et al. 2009, Sherman et al. 2017).

Severe "melting" corneal lesions often require surgical therapy due to the high risk of corneal perforation. Additionally, pathogenic fungi appear to have a specific affinity to the posterior stroma and the Descemet's membrane, enhancing the risk for abscess formation (Brooks et al. 2017). In the case described, the foal showed severe signs of keratomalacia and was unresponsive to topical medical therapy. Thus, surgical therapy was conducted. Surgical intervention in horses suffering from keratomalacia incorporates debridement of the lesion to remove the necrotic or melted tissue and subsequent reconstruction of the cornea (Gelatt et al. 2013). The purpose of corneal reconstruction with different corneal grafts is to enable the migration and differentiation of epithelial cells, reinforcement of cellular adhesion and decrease of the ocular surface inflammation. The main goal is to achieve healing without impairing long-term corneal transparency.

Previous literature describes the use of different biomaterials as corneal grafts in horses (Bussieres et al. 2004, Lassaline et al. 2005, Plummer 2009, Mancuso et al. 2016, Davis et al. 2019). Conjunctival grafting is the most wide-spread technique for this condition (Gelatt et al. 2013). Conjunctival autografts support the corneal healing with the patient's own cellular and acellular components and vascular supply. It provides sufficient tissue to strengthen weakened corneas, but often results in corneal scars that can impair the vision and occasionally perforates due to insufficient mechanical support (Ollivier 2005, Brooks 2008, Brooks et al. 2017). Other biomaterials, such as equine amnion (Lassaline et al. 2005, Plummer 2009), porcine urinary bladder (Mancuso et al. 2016, Davis et al. 2019) and porcine small intestinal submucosa (Bussieres et al. 2004) caused less scarring and resulted in better corneal transparency in equine patients. Transplantation of allogenic amniotic membranes has been used successfully for ocular surface reconstruction in horses (Lassaline et al. 2005, Plummer 2009). Amnion consists of a thick basement membrane and an avascular stromal matrix. The relatively acellular and strong tissue makes it suitable as a corneal graft. However, the lack of commercial availability for veterinary medicine and, thus, the necessity of donor horses to acquire fresh or stored graft material limited its use in the recent past (Plummer 2009). Porcine SIS and porcine urinary bladder are both extracellular matrix (ECM) products which have resulted in good corneal transparency (Bussieres et al. 2004, Mancuso et al. 2016, Davis et al. 2019). The lack of cellular components is thought to be associated with a reduced immune response, which could affect graft rejection. The ECM forms a scaffold for cellular and vascular ingrowth and provides different endogenous growth factors (Bussieres et al. 2004, Vanore et al. 2007, Mancuso et al. 2016). Both products are currently commercially available for veterinary use. 
BioSIS Plus ${ }^{+}$is produced from the porcine jejunum. The superficial layers of the tunica mucosa, the tunica muscularis externa and the tunica serosa are removed. The remaining tissue represents the SIS and consists of the tunica submucosa and basilar layers of the tunica mucosa. The tissue is decellularized and consists entirely of ECM (Vanore et al. 2007). Each BioSIS Plus ${ }^{+}$graft consists of four of these single layer grafts lying upon another (Barachetti et al. 2016). The acellular collagen matrix acts as a scaffold medium for fibroblasts which are later replaced by corneal stroma cells (Vanore et al. 2007). The ECM product also consists of fibronectin, hyaluronic acid, chondroitin sulphate, heparin sulphate and growth factors (Vanore et al. 2007). Among these, transforming growth factor-beta has also been shown to inhibit the synthesis of metalloproteinases (Roberts et al. 1990).

Postoperatively, the graft material is prone to desiccation or mechanical irritation by continuous eyelid movement or abrasion due to pruritus. Covering the graft material can prevent implant failure (Goulle 2012). Conjunctival flaps (Bussieres et al. 2004) or a temporary tarsorrhaphy (Mancuso et al. 2016, Davis et al. 2019) have been used to cover porcine SIS or urinary bladder grafts in horses in the past. The large size of the defect in this case impeded the use of a conjunctival graft to cover the SIS grafts. Although, conjunctival grafts can lead to an enhanced opacity of the cornea, as described previously. The use of a temporary tarsorrhaphy precludes the clinical evaluation of the affected eye in the postoperative period (Mancuso et al. 2016). This is important, as keratomalacia is often related to some degree of iridocyclitis (Brooks et al. 2017). Thus, tarsorrhaphy was routinely partially opened at three to five days postoperatively in a previous study to allow the evaluation of globe integrity, peripheral corneal and anterior chamber transparency and pupil size (Mancuso et al. 2016). Potential benefits of a prolonged time of temporary tarsorrhaphy may lead to improved corneal comfort, providence of structural support to the surgical site and an increased corneal contact time of topical medications (Mancuso et al. 2016).

Compared to previous descriptions, we used porcine SIS grafts (BioSIS Plus ${ }^{+}$), which consist of four single layers laminated together. The enhanced thickness of this material makes it more resistant to mechanical irritation, which minimises the need for an additional coverage. In the case described, the corneal surface and the adjacent grafts have been protected by closed eyelids, maintained by a head bandage, for eight days. No tarsorrhaphy was performed. This enabled simple investigation of graft integrity at every bandage change. Subsequently, the cornea was left uncovered. At six days postoperatively, a decreased thickness of the graft material was observed, potentially provoked by mechanical irritation. Hypothetically, this could have led to graft failure if a less resistant material, such as single-layer SIS or urinary bladder grafts, were used. Desiccation, direct mechanical irritation or implant failure were not observed at any time. Progressive clearing of the cornea with only very mild impairment of vision was observed during follow-up examinations.

Due to the surgeon's personal experience, post-operatively $1 \%$ voriconazole has been injected intracameral. Intracameral injection of voriconazole did not induce a significant gross change in rabbit corneal endothelial cells up to a concentra- tion of $1 \%$. However, risk of microstructural damages might exist with a concentration of $\geq 0.25 \%$ (Han et al. 2012).

To conclude, the use of multilayer SIS grafts is an appropriate technique for the treatment of horses suffering from mycotic corneal ulcers and accessory keratomalacia. Furthermore, this report shows that covering the grafts with a replaceable head bandage instead of tarsorrhaphy or an additional conjunctival flap can be beneficial in different aspects.

\section{Author's declaration of interests}

No conflicts of interest have been declared.

\section{Ethical animal research}

Not applicable

\section{Source of funding}

No funding received

\section{Authorship}

All authors collaborated in case management. Alexander Schwieder prepared the manuscript. All authors gave their final approval of the manuscript.

\section{Manufacturers' addresses}

1 CP-Pharma Handelsgesellschaft mbH, Burgdorf, Germany

2 Wirtschaftsgenossenschaft deutscher Tierärzte eG, Garbsen, Germany

3 Laboratoire TVM, Lempdes, France

4 Novartis Pharma GmbH, Nürnberg, Germany

5 Pfizer Deutschland $\mathrm{GmbH}$, Berlin, Germany

6 Ursapharm Arzneimittel GmbH, Saarbrücken, Germany

7 Vetoquinol GmbH, Ismaring, Germany

8 Ecuphar GmbH, Greifswald, Germany

9 Ratiopharm GmbH, Ulm, Germany

10 Hameln pharma plus GmbH, Hameln, Germany

1 Serumwerk Bernburg, Bernburg, Germany

12 Vetrix, Cumming, GA, USA

13 Johnson \& Johnson, New Brunswick, New J, USA

${ }^{14}$ ROGG Verbandsstoffe GmbH \& Co. KG, Fahrenzhausen, Germany

\section{References}

Aiken S. W., Badylak S. F., Toombs J. P., Shelbourne K. D., Hiles M. C., Lantz G. C., Van Sickle D. (1994) Small Intestinal Submucosa as an Intra-Articular Ligamentous Graft Material: A Pilot Study in Dogs. Vet. Comp. Orthop. Traumatol. 7, 124-128; DOI 10.1055/s-0038-1633133

Andrew S. E., Brooks D. E., Biros D. J., Denis H. M., Cutler T. J., Gelatt K. N. (2000) Posterior lamellar keratoplasty for treatment of deep stromal absesses in nine horses. Vet. Ophthalmol. 3, 99-103; DOI 10.1046/i.1463-5224.2000.00129.x 
Andrew S. E., Brooks D. E., Smith P. J., Gelat K. N., Chmielewski N. T., Whittaker C. J. G. (1998) Equine ulcerative keratolmycosis: visual outcome and ocular survival in 39 cases ( 109-116). Equine Vet. J. 30, 109-116

Badylak S. F., Lantz G. C., Coffey A., Geddes L. A. (1989) Small intestinal submucosa as a large diameter vascular graft in the dog. J. Surg. Res. 47, 74-80. DOI 10.1016/0022-4804(89)90050-4

Barachetti L., Zanni M., Rampazzo A. (2016) the Use of 4-Layer Porcine Small Intestinal Submucosa As Single Scaffold for the Treatment of Deep Corneal Defects in Cats and Dogs : Preliminary Data.

Brooks D. E. (1999) Equine ophthalmology. Veterinary Ophthalmology. Willimas \& Wilkins: Philadelphia, USA. pp. 1053-1116.

Brooks D. E. (2008) Ophthalmology for the Equine Practitioner. Teton NewMedia: Jackson, USA

Brooks D. E. (2010) Targeted lamellar keratoplasty in the horse: A paradigm shift in equine corneal transplantation. Equine Vet. J. 42, 24-30; DOI 10.1 111 /j.2042-3306.2010.tb05631.x

Brooks D. E., Andrew S. E., Dillavou C. L., Ellis G., Kubilis P. S. (1998) Antimicrobial susceptibility patterns of fungi isolated from horses with ulcerative keratomycosis. Am. J. Vet. Res. 59, 138-142

Brooks D. E., Matthews A., Clode A. B. (2017) Disease of the cornea. Equine Ophthalmology. Wiley-Blackwell: Hoboken, USA. 252-368

Brooks D. E., Plummer C. E., Kallberg M. E., Barrie K. P., Ollivier F. J., Hendrix D. V. H., Baker A., Scotty N. C., Utter M. E., Blackwood S. E., Nunnery C. M., Ben-Shlomo G., Gelatt K. N. (2008) Corneal transplantation for inflammatory keratopathies in the horse: Visual outcome in 206 cases (1993-2007). Vet. Ophthalmol. 11, 123-133; DOI 10.1111/j.1463-5224.2008.00611.x

Brooks D. E., Plummer C. E., Mangan B. G., Ben-Shlomo G. (2013) Equine subepithelial keratomycosis. Vet. Ophthalmol. 16, 93-96; DOI 10.1111/j.1463-5224.2012.01031.x

Bussieres M., Krohne S. G., Stiles J., Townsend W. M. (2004) The use of porcine small intestinal submucosa for the repair of full-thickness corneal defects in dogs, cats and horses. Vet. Ophthalmol. 7, 352-359; DOI 10.1111/j.1463-5224.2004.04055.x

Cichocki B., Myrna K., Moore P. (2017) Modified penetrating keratoplasty with Acell $\circledast$ bioscaffold implant in seven horses with deep full-thickness corneal stromal abscess. Vet. Ophthalmol. 20, 4652; DOI 10.1111/vop.12349

Coad C. T., Robinson N. M., Wilhelmus K. R. (1985) Antifungal sensitivity testing for equine keratomycosis. Am. J. Vet. Res. 46, 676-678

Cobb M. A., Badylak S. F., Janas W., Simmons-Byrd A., Boop F. A. (1999) Porcine small intestinal submucosa as a dural substitute. Surg. Neurol. 51, 99-104; DOI 10.1016/\$00903019(97)00475-8

Davis A. M., Riggs C. M., Chow D. W. Y. (2019) The use of porcine urinary bladder matrix (UBM) to repair a perforated corneal ulcer with iris prolapse in a horse. Equine Vet. Educ. 31, 172-178; DOI 10.1111/eve.12779

Dejardin L. M., Arnoczky S. P., Clarke R. B. (1999) Use of small intestinal submucosal implants for regeneration of large fascial defects: An experimental study in dogs. J. Biomed. Mater. Res. 46, 203 211 ; DOI 10.1002/ (SICI) 1097-4636(199908)46:2 < 203::AIDJBM9 > 3.0.CO;2-4

Derwin K., Androina C., Spencer E., Safran O., Baver T. W., Hunt T., Caplan A., lannotti J. (2004) Porcine Small Intestine Submucosa as a Flexor Tendon Graft. Clin. Orthop. Relat. Res. 423, 245-252; DOI 10.1097/01.blo.0000131235.91264.d7

Ding J.-X., Chen L.-M., Zhang X.-y., Zhang Y., Hua K.-Q. (2015) Sexval and functional outcomes of vaginoplasty using acellular porcine small intestinal submucosa graft or laparoscopic peritoneal vaginoplasty: a comparative study. Hum. Reprod. 30, 581-589; DOI 10.1093/humrep/deu34 1

Featherstone H. J., Sansom J. (2004) Feline corneal sequestra: A review of 64 cases (80 eyes) from 1993 to 2000. Vet. Ophthalmol. 7, 213-227; DOI 10.1111/j.1463-5224.2004.04028.x
Fiala R., Vidlar A., Vrtal R., Belej K., Student V. (2007) Porcine Small Intestinal Submucosa Graft for Repair of Anterior Urethral Strictures. Eur. Urol. 51, 1702-1708; DOI 10.1016/i.eururo.2007.01.099

Fini M. E., Cook J. R., Mohan R. (1998) Proteolytic mechanisms in corneal ulceration and repair. Arch. Dermatol. Res. 290, 12-23; DOI 10.1007/PL00007449

Galán A., Martín-Suárez E. M., Gallardo J. M., Molleda J. M. (2009) Clinical findings and progression of 10 cases of equine ulcerative keratomycosis (2004-2007). Equine Vet. Educ. 21, 236-242; DOI 10.2746/095777309X400289

(2001) Meniscal tissue regeneration using a collagenous biomaterial derived from porcine small intestine submucosa. Arthrosc. J. Arthrosc. Relat. Surg. 17, 151-159; DOI 10.1053/jars.2001.20959

Gelatt K. N., Gilger B. C., Kern T. J. (2013) Veterinary Ophthalmology. Wiley-Blackwell: Hoboken, USA

Goulle F. (2012) Use of porcine small intestinal submucosa for corneal reconstruction in dogs and cats: 106 cases. J. Small Anim. Pract. 53, 34-43; DOI 10.1111/j.1748-5827.2011.01149.x

Han S. B., Yang H. K., Hyon J. Y., Shin Y. J., Wee W. R. (2012) Toxicity of voriconazole on corneal endothelial cells in an animal model. Br. J. Ophthalmol. 96, 905-908; DOI 10.1136/bjophthalmol-2011-301129

Kessler E., Kennah H. E., Brown S. I. (1977) Pseudomonas protease. Purification, partial characterization, and its effect on collagen, proteoglycan, and rabbit corneas. Invest. Ophthal. Visual Sci. 16, 488-497

Lantz G. C., Badylak S. F., Coffey A. C., Geddes L. A., Blevins W. E. (1990) Small intestinal submucosa as a small-diameter arterial graft in the dog. J. Investig. Surg. 3, 217-227; DOI 10.3109/08941939009140351

Lassaline M. E., Brooks D. E., Ollivier F. J., Komaromy A. M., Kallberg M. E., Gelatt K. N. (2005) Equine amniotic membrane transplantation for corneal ulceration and keratomalacia in three horses. Vet. Ophthalmol. 8, 311-317; DOI 10.1111/j.14635224.2005.00405.x

Ledbetter E. C., Patten V. H., Scarlett J. M., Vermeylen F. M. (2007) In vitro susceptibility patterns of fungi associated with keratomycosis in horses of the northeastern United States: 68 cases (19872006). J. Am. Vet. Med. Assoc. 231, 1086-1091; DOI 10.2460/ javma.231.7.1086

Lewin G. A. (1999) Repair of a full thickness corneoscleral defect in a German shepherd dog using porcine small intestinal submucosa. J. Small Anim. Pract. 40, 340-342; DOI 10.1111/j.17485827. 1999.tb03094.x

de Linde Henriksen M., Plummer C. E., Mangan B., Ben-Shlomo G., Tsujita H., Greenberg S., Toft N., Brooks D. E. (2012) Visual outcome after corneal transplantation for corneal perforation and iris prolapse in 37 horses: 1998-2010. Equine Vet. J. 44, 115-119; DOI 10.1111/i.2042-3306.2012.00657.x

Mancuso L. A., Lassaline M., Scherrer N. M. (2016) Porcine urinary bladder extracellular matrix grafts (ACell Vet ${ }^{\circledR}$ Corneal Discs) for keratomalacia in 17 equids (2012-2013). Vet. Ophthalmol. 19, 3-10; DOI 10.1111/vop.12240

Matsubara M., Girard M. T., Kublin C. L., Cintron C., Fini M. E. (1991) Differential roles for two gelatinolytic enzymes of the matrix metalloproteinase family in the remodelling cornea. Dev. Biol. 147, 425-439; DOI 10.1016/0012-1606(91)90300-R

Matsumoto K. (2000) Proteases in bacterial keratitis. Cornea 19, 160-164; DOI 10.1097/00003226-200000003-00005

Moore C. P., Heller N., Majors L. J., Whitley R. D., Burgess E. C., Weber J. (1988) Prevalence of ocular microorganisms in hospitalized and stabled horses. Am. J. Vet. Res. 49, 773-777

Nasisse M. P., Nelms S. (1992) Equine Ulcerative Keratitis. Vet. Clin. North Am. Equine Pract. 8, 537-555; DOI 10.1016/S0749. 0739(17)30440-6

Ollivier F. J. (2005) Medical and Surgical Management of Melting Corneal Ulcers Exhibiting Hyperproteinase Activity in the Horse. Clin. Tech. Equine Pract. 4, 50-71; DOI 10.1053/i. ctep.2005.03.012 
Ollivier F. J., Gilger B. C., Barrie K. P., Kallberg M. E., Plummer C. E., O'Reilly S., Gelatt K. N., Brooks D. E. (2007) Proteinases of the cornea and preocular tear film. Vet. Ophthalmol. 10, 199-206; DOI 10.1111/j.1463-5224.2007.00546.x

Plummer C. E. (2009) The use of amniotic membrane transplantation for ocular surface reconstruction: A review and series of 58 equine clinical cases (2002-2008). Vet. Ophthalmol. 12, 17-24; DOI 10.1111/i.1463-5224.2009.00741.x

Roberts A. B., Heine U. I., Flanders K. C., Sporn M. B. (1990) Transforming Growth Factor- $\beta$ : Major Role in Regulation of Extracellular Matrix. Ann. N. Y. Acad. Sci. 580, 225-232; DOI 10.1111/ j.1749-6632.1990.tb17931.x

Samuelson D. A., Andresen T. L., Gwin R. M. (1984) Conjunctival fungal flora in horses, cattle, dogs, and cats. J. Am. Vet. Med. Assoc. 184, 1240-1242

Sansom J., Featherstone H., Barnett K. C. (2005) Keratomycosis in six horses in the United Kingdom. Vet. Rec. 156, 13-17; DOI $10.1136 / v r .156 .1 .13$

Sherman A. B., Clode A. B., Gilger B. C. (2017) Impact of fungal species cultured on outcome in horses with fungal keratitis. Vet. Ophthalmol. 20, 140-146; DOI 10.1111/vop.12381

Sivak J. M., Fini M. E. (2002) MMPs in the eye: emerging roles for matrix metalloproteinases in ocular physiology. Prog. Retin. Eye Res. 21, 1-14; DOI 10.1016/S1350-9462(01)00015-5

Strubbe D. T., Brooks D. E., Schultz G. S., Willis-Goulet H., Gelatt K. N., Andrew S. E., Kallberg M. E., Mackay E. O., Collante W. R. (2000) Evaluation of tear film proteinases in horses with ulcerative keratitis. Vet. Ophthalmol. 3, 111-119; DOI 10.1046/j.14635224.2000.00093.x
Suckow M., Voytik-Harbin S., Terril L., Badylak S. (1999) Enhanced Bone Regeneration Using Porcine Small Intestinal Submucosa. J. Investig. Surg. 12, 277-287; DOI 10.1080/089419399272395

Thomas P. A. (2003) Fungal infections of the cornea. Eye 17, 852862; DOI 10.1038/sj.eye.6700557

Twining S. S., Fukuchi T., Yue B. Y. J. T., Wilson P. M., Boskovic G. (1994) Corneal synthesis of $\alpha 1$-proteinase inhibitor ( $\alpha 1$-antitrypsin). Investig. Ophthalmol. Vis. Sci. 35, 458-462

Twining S. S., Fukuchi T., Yue B. Y. J. T., Wilson P. M., Zhou X. (1994) Alpha-2 macroglobulin is present in and synthesized by the cornea. Curr. Eye Res. 13,433-439; DOI 10.3109/02713689408999871

Vanore M., Chahory S., Payen G., Clerc B. (2007) Surgical repair of deep melting ulcers with porcine small intestinal submucosa (SIS) graft in dogs and cats. Vet. Ophthalmol. 10, 93-99; DOI 10.1111/j.1463-5224.2007.00515.x

Whitley R. D., Burgess E. C., and Moore C. P. (1983) Microbial isolates of the normal equine eye. Equine Vet. J. 138-140; DOI 10.11 11 /i.2042-3306.1983.tb04578.x

Whittaker C. J. G., Smith P. J., Brooks D. E., Hendrix D. V., Chmielewski N. T., Andrew S. E., Gelatt K. N. (1997) Therapeutic penetrating keratoplasty for deep corneal stromal abscesses in eight horses. Vet. Comp. Ophthalmol. 7, 19-28

Wilson S. E., Mohan R. R., Mohan R. R., Ambrósio R., Hong J., Lee J. (2001) The Corneal Wound Healing Response: Cytokine-mediated Interaction of the Epithelium, Stroma, and Inflammatory Cells. Prog. Retin. Eye Res. 20, 625-637; DOI 10.1016/S1350-9462(01)00008-8

Zhu W.-S., Wojdyla K., Donlon K., Thomas P. A., Eberle H. I. (1990) Extracellular proteases of Aspergillus flavus: Fungal keratitis, proteases, and pathogenesis. Diagn. Microbiol. Infect. Dis. 13, 491497; DOI 10.1016/0732-8893(90)90081-6 